\title{
EMPREGO DA AZIDA SÓDICA, COMO CONSERVADOR DE FEZES, PARA A PESQUISA DE OVOS DE SCHISTOSOMA MANSONI E DE OUTROS HELMINTOS, PELO MÉTODO DE KATO-KATZ: ESTUDO EM ÁREA ENDÊMICA
}

\author{
Vicente Amato Neto, Pedro Luiz Silva Pinto, Ogvalda Dawey de Souza \\ Torres, Luís Matsubara, Lúcia Maria Almeida Braz e Sérgio Antonio Barbosa \\ do Nascimento
}

\begin{abstract}
Em duas alíquotas de 208 amostras de fezes foramfeitos exames pelo método de Kato-Katz, sendo uma após o emprego de $0,2 \mathrm{mg}$ de azida sódica para $200 \mathrm{mg}$ e em outra sem o referido conservador. Os resultados percentuais com e sem conservador foram, respectivamente, para os Ancilostomideos 12,5 e 25,9, para Ascaris lumbricoides 71,6 e 72,5, para Schistosoma mansoni 7,6 e 17,7 e para Trichuris trichiurá 86 e 85. A contagem dos ovos com e sem o conservador foi, respectivamente, 264 e 539 para os Ancilostomideos, 13816 e 33751 para A. lumbricoides, 55,5 e 63,5 para S. mansoni e 1345 e 2068 para $\mathrm{T}$. trichiura. Os autores não confirmaram a vantagem do uso de azida sódica para estudo em áreas endêmicas. Sugerem que o ressecamento das fezes e a baixa intensidade das infecções possam explicar os resultados desfavoráveis do presente ensaio clínico.
\end{abstract}

Palavras-chaves: Esquistossomose mansônica. Exame de fezes. Azida sódica. Área endêmica.

O método de Kato-Katz é utilizado em análises qualitativas e quantitativas de fezes, para diagnóstico de helmintíases intestinais e, em especial, da esquistossomíase. Trata-se de técnica bastante utilizada no Brasil, em virtude de efetividade, fácil execução, custo não elevado, necessidade de pequena quantidade de material fecal e possibilidade de examinar as lâminas até seis meses depois de preparadas ${ }^{4}$. A despeito dessas virtudes, há empecilho relacionado com trabalhos de campo, quando pode existir razoável período de tempo entre a coleta do material e o procedimento laboratorial.

$O$ uso de tradicionais conservadores gera dificuldade, uma vez que eles liquefazem as fezes. Nesse contexto, lembramos que a azida sódica é um fixador sólido, possuidor de ação preservadora a propósito de ovos de helmintos, conforme já foi demonstrado e, em estudo sobre essa tática, houve verificação de que conservou satisfatoriamente

\footnotetext{
Laboratório de Investigação Médica/Parasitologia, Hospital das Clínicas, Faculdade de Medicina, Universidade de São Paulo, São Paulo, SP.

Endereco para correspondência: Prof. Vicente Amato Neto. Laboratório de Investigação Médica-Parasitologia/HC/FM/ USP. Av. Dr. Arnaldo 455, $2^{\circ}$ andar, 01246-000 Sāo Paulo, SP.

Recebido para publicação em 13/07/92.
}

amostras contendo ovos de Schistosoma mansoni até 12 semanas após a adição ${ }^{12}$.

Pareceu-nos necessário avaliar concretamente a validade do referido processo, dependente da azida sódica, na atividade desempenhada emárea endêmica de esquistossomíase, quando cogitados intentos diagnósticos e, mormente, epidemiológicos.

\section{MATERIAL E MÉTODOS}

A investigação baseou-se em 208 amostras fecais, acondicionadas em pequenos recipientes de plástico aptos a facilitar transporte, correspondentes a habitantes da bacia hidrográfica do Rio Paraguaçu, no Estado da Bahia. De cada parte separamos duas alíquotas, para processamento de uma sem o conservador e da outra posteriormente à adição de 0,2 $\mathrm{mg}$ de azida sódica para $200 \mathrm{mg}$, de molde a compor valores iguais a um décimo dos preferidos por Gonçalves e cols ${ }^{2}$, com o fito de simplificar a funcionalidade; de início, pesamos essas quantidades e subseqüentemente agimos por estimativas. As frações sem o fixador foram logo examinadas no Laboratório do Instituto de Saúde, da Universidade Federal da Bahia, por meio do método de Kato-Katz, e as outras tiveram encaminhamento ao Laboratório de Invetigação Médica-Parasitologia do Hospital das 
Amato Neto V, Pinto PLS, Torres ODS, Matsubara L, Braz LMA, Nascimento SAB. Emprego da azida sódica como conservador de fezes para a pesquisa de ovos de Schistosoma mansoni e de outros helmintos, pelo método de KatoKatz: estudo em área endêmica. Revista da Sociedade Bräsileira de Medicina Tropical 25:161-163, jul-set, 1992.

Clínicas, da Faculdade de Medicina da Universidade de São Paulo, onde ficaram em temperatura ambiente durante 30 dias, para efetivação de idêntica análise ${ }^{4}$. Em virtude do ressecamento, houve comumente imperiosidade no sentido de juntar duas ou três gotas de água aos espécimes preservados, surgindo a impressão de que isso não se mostrou sempre satisfatório.

\section{RESULTADOS}

As fezes conservadas mostraram-se mais escurecidas, sem produção de gás e com odor discreto, provavelmente como consequiência de menor atividade de microorganismos.

Constatamos que a grande maioria das amostras estava ressecada, exigindo reidratação, e que os ovos não apresentaram alterações morfológicas capazes de prejudicar as identificações.

Registramos 13 procuras totalmente negativas e com referência aos ovos dos quatro tipos de helmintos detectados apuramos as seguintes positividades: Ancilostomídeos - 34,6\% (72/208); Ascaris lumbricoides -75,4\% (157/208); S. mansoni - 20,1\% (42/208); Trichuris trichiura - 87,9\% (183/208).

Nas Tabelas 1 e 2 especificamos, detalhadamente, dados acerca das contagens e as evidenciações específicas, levando em conta as duas modalidades comparadas.

Só uma vez apareceram ovos de Enterobius vermicularis.

Tabela 1 - Porcentagem de positividades decorrentes de exames parasitológicos defezes, efetuados pelo método de Kato-Katz, sem ou com conservação, durante 30 dias, pela azida sódica.

\begin{tabular}{lcc}
\hline Helmintos & \multicolumn{2}{c}{ Conservador } \\
\cline { 2 - 3 } & Não & Sim \\
\hline Ancilostomídeo & 25,9 & 12,5 \\
Ascaris lumbricoides & 72,5 & 71,6 \\
Schistosoma mansoni & 17,7 & 7,6 \\
Trichuris trichiura & 85 & 86 \\
\hline
\end{tabular}

Tabela 2 - Resultados de exames de fezes, efetuados pelo método de Kato-Katz, sem ou com conservação, durante 30 dias, pela azida sódica: números mínimo e máximo de ovos por grama de fezes, quantidades médias dessas cifras e positividades exclusivas.

\begin{tabular}{lrr}
\hline \multirow{2}{*}{ Helmintos } & \multicolumn{2}{c}{ Conservador } \\
\cline { 2 - 3 } & Não & Sim \\
\hline \multirow{2}{*}{ Ancilostomídeo } & 5394 & 24 a 1344 \\
& 46 & 264 \\
& & 18 \\
Ascaris lumbricoides & 48 a 612816 & 24 a 91776 \\
& 33751 & 13816 \\
& 8 & 6 \\
Schistosoma mansoni & 24 a 336 & 24 a 288 \\
& 63,5 & 55,5 \\
& 26 & 5 \\
Trichuris trichiura & 24 a 23568 & 24 a 24808 \\
& 2068 & 1345 \\
& 4 & 5 \\
\hline
\end{tabular}

\section{DISCUSSÃO}

Focalizada a esquistossomíase mansônica, notamos que a porcentagem de diagnósticos definidos quando adicionado o conservador diminuiu sensivelmente, sem todavia ver-se queda dos números de ovos, quando positivos os materiais.

$O$ fixador não prejudicou de forma marcante $o$ reconhecimento do Trichuris, tendo porém influído bastante nas quantidades atinentes à ancilostomíase. Por seu turno, a ascaridíase continuou a ser bem confirmada, em geral através de valores menores de números de ovos.

Com a aplicação da azida sódica, previamente aos exames pela técnica de Kato-Katz, em determinadas oportunidades ocorreram encontros exclusivos de ovos e, excetuada a tricuríase, com menor freqüência do que se esclareceu sem a participação dela.

Como tentativa de explicar o desempenho bem diverso do informado por Gonçalves e cols ${ }^{2}$, no que tange aos ovos de $S$. mansoni, ocorrem-nos duas eventuais justificativas: a) apesar de respeitarmos as diretrizes que norteiam a execução do método de Kato-Katz, contamos com poucas quantidades de 
Amato Neto V, Pinto PLS, Torres ODS, Matsubara L, Braz LMA, Nascimento SAB. Emprego da azida sódica como conservador de fezes para a pesquisa de ovos de Schistosoma mansoni e de outros helmintos, pelo método de KatoKatz: estudo em área endêmica. Revista da Sociedade Brasileira de Medicina Tropical 25:161-163, jul-set, 1992.

fezes, acondicionadas em exíguos batoques, escolhidos para facilitar o transporte e esse modo de agir provocou mais ressecamentos, impondo-se rememorar que os autores citados procuraram proceder com aproximadamente $2 \mathrm{~g}$ iniciais; $\mathrm{b}$ ) as intensidades das infecções, de reduzidos portes, quiçá também tenham cooperado 35 .

Para o visto com referência aos ovos de ancilostomídeo, é viável julgar que se deu ação prejudicial da glicerina, por alguma demora antes do exame, estando os materiais processados.

Estas verificaçãoes, não auspiciosas, desmerecem a almejada boa atividade conservante da azida sódica em labores como o delineado neste estudo. $O$ que outras pésquisas previamente mostraram era mais animador. Não obstante, vale a pena continuar coletando novas deduções, sobretudo atentando para esmeros de ordem operacional.

\section{SUMMARY}

In two aliquots of 208 samples of stool, tests have been made by the Kato-Katz method, one being made after the use of $0.2 \mathrm{mg}$ of sodic azide for $200 \mathrm{mg}$, and the other without the aforesaid conservant. The resulted percentages with or without the conservant were, respectively, for Ancylostomideos: 12.5 and 25.9; for Ascaris lumbricoides: 71.6 and 72.5; for Schistosoma mansoni: 7.6 and 17.7, and for Trichuris trichiura: 86 and 85. The count of the eggs with and without the conservant was, respectively, 264 and 539 for Ancylostomideos, 13186 and 33751 for A. lumbricoides, 55.5 and 63.5 for $\mathrm{S}$. mansoni, and 1345 and 2068 for $\mathrm{T}$. trichiura. The authors did not confirm the advantage of using sodic azide for study in endemic areas. They suggest that the exsiccation of the stool and the low intensity of infections can explain the unfavourable results of the present clinical trial.

Key-words: Schistosomiasis mansoni. Stool test. Sodic azide. Endemic area.

\section{REFERÊNCIAS BIBLIOGRÁFICAS}

1. Bundy DAP, Foreman JDM, Golden MHN. Sodium azide preservation of faecal specimens for Kato analysis. Parasitology 90:463-469, 1985.

2. Gonçalves EMN, Campos $R$, Amato Neto $V$, Pinto PLS, Moreira AAB. Emprego da azida sódica, como conservador de fezes, para pesquisa de ovos de Schistosoma mansoni pelo método de Kato-Katz. Revista da Sociedade Brasileira de Medicina Tropical 21:59-62, 1988

3. Jordan P, Bartholomew RK, Peters PAS. A community study of Schistosoma mansoni egg excretion assessed by the Bell and a modified Kato technique. Annals of Tropical Medicine and Parasitology 75:35-40, 1981.

4. Katz N, Chaves A, Pelegrino J. A simple device for quantitative stool thick-smear technique in schistosomiasis mansoni. Revista do Instituto de Medicina Tropical de São Paulo 14:397-400, 1972.

5. Knight WB, Hiatt RA, Cline BL, Ritchie LS. A modification of the formol-ether concentration technique for increased sensitivity en detection Schistosoma mansoni eggs. The American Journal of Tropical Medicine and Hygiene 25:818-823, 1976. 